\title{
ADVERTISEMENTS ON THE TREATMENT OF VENEREAL. DISEASES IN THE EIGHTEENTH AND NINETEENTH CENTURIES
}

Dr. A. Fessler, Venereal Diseases Officer, Lancashire County Council, and Mr. R. Sharpe France, the County Archivist, have found in some old newspapers deposited in the County Archives at Preston a number of interesting advertisements dealing with the treatment of venereal diseases. These are somewhat similar to the leaflets published in an article by Dr. Fessler in this Journal in June, 1946 , page 85 , but they cover a longer period of time, and Dr. Fessler draws attention to the changing attitudes towards this group of diseases as reflected in the terminology used. In the advertisements of the eighteenth century, for example, syphilis is named and terms such as "Claps and French illness" are used. A change of outlook is shown in an advertisement of a later period, where venereal diseases are now named as "certain diseases." The names of the various venereal diseases reappear in the thirties of the last century.

Dr. Fessler writes, "The number of advertisements dealing with venereal diseases is small compared with advertisements dealing with other diseases. I can find only two advertisements dealing with the treatment of gonorrhœa, one of which is quack treatment at its worst, suggesting cubebs with sarsaparilla for the treatment of gonorrhœa as well as for syphilis. Another advertisement suggests the use of soap as a preventative, but this has no signature and seems to have been inserted by a soap manufacturer.

It is interesting to note that venereal diseases must have been prevalent to a certain extent in the provinces, not only in industrial and mining areas, such as Blackburn and Wigan, but even in typical rural areas, such as Lancaster and Kendal, at the beginning of the nineteenth century, probably as a result of the Napoleonic wars."

\section{Eighteenth-Century Advertisements}

The following advertisement is from the London Evening Post of Feb. 19-22, 1732.

\section{ANTI-SYPHILICON}

The only short and most infallible CURE in the Universe for the Venereal Disease, from the slightest Infection to the most extreme and deplorable Degree of it, even when the Blood and Juices are thoroughly contaminated with its malignant Virus, and the very Bones are affected with it:

Fresh Infections, call'd Claps, with all their attendant Symptoms, tho' ever so severe, are entirely carried off by it in a few days, and so as effectually to prevent the Blood and Juices from being tainted with any remaining Relicts on one Hand, or a seminal Gleet or Weakness to happen on the other.

And the most inveterate Degree of the French Illness, attended with Nocturnal Pains, universal Breakings out, and all other the most exasperated Symptoms, are soon overcome by it, and effectually and much more safely cured than by Salivation, Inungation, or any other Method whatever, and in so easy and pleasant a Manner, without impairing Strength, or occasioning Inconvenience, as loudly to bespeak it the only apposite Remedy or true Venereal Antidote in the World; and this some Thousands have to their great Joy experienc'd.

It is pleasant to take, occasions no Sickness or Disorder, nor requires Confinement ; but may be taken, and the Cure be accomplish'd, without the Knowledge of the nearest Friend.

Those who suspect they have received an Injury, may, by only a Dose or two of it, be perfectly freed from all Apprehensions ; for it suffers no lurking Venom to lie hid in the Body, but wholly extirpates it Root and Branch, in a gentle, easy, and most effectual Manner.

All such likewise as doubt they have some remaining Relicks of former Injuries, may by a few Doses of it intirely free themselves from all Suspicions of that Kind; for it admits of no Foulness, Corruption, or Putrefaction whatever to remain in the Fluids, or to adhere to the Solids ; and on that Account, in all scorbutick, scrophulous, and even Leprous Eruptions or Foulnesses of the Skin, Glandulous Swellings and Impurities of the Juices, it does more by one Dose than any other Medicine yet known can by ten.

The Price of this most noble Anti-Syphilicon is but Six Shillings a Pot, which considering its 
extraordinary Efficacy, one Pot only being sufficient in most Cases to accomplish the Cure, is not a tenth Part of its Value ; and is appointed by the Author to be had only at Mr. Radford's Toyshop, at the Rose and Crown against St. Clement's Church-yard in the Strand, ready seal'd up with a Book of Instructions, by the Perusal of which, all Persons who were ever affected with any Degree of the Venereal Disease, may perfectly understand their own Condition, and certainly know when, and when not, the Venereal Poison is entirely rooted out of their Bodies.

Note. Ask only for a Six Shilling Pot for the Scurvy.

The following is from an issue of the same newspaper dated Nov. 29-Dec. 1, 1750.

\section{For the VENEREAL DISEASE}

THE shortest, safe and regular, Cure this Day in the World, from the slightest Infection to the most inveterate Degree of it, by a Medicine as pleasant to take, and as easy in its Operation as it is effectual for a thorough Cure; so that the unfortunate Patient gets suddenly and surprizingly well, without Distaste to his Palate, the least Disorder of Body, or any Confinement whatever. This is that great Remedy, now so well known and long experienced to be truly infallible, and is the Grand ANTI-SYPHLICON that Radcliffe and Garth* used to say would totally extirpate the Venereal Disease from the Face of the Earth, were it but universally known, and properly taken. Fresh Infections, call'd Claps, with all their cruel attendant Symptoms, it presently cures ; and if taken in time, even prevents their taking Place. It is a safe, gentle, and pleasant Family Purge, even for Children as well as grown Persons, in all Cases where Purging is necessary; nor can the deepest Scurvy, Rheumatism, Gout, Evil or Leprosy, stand before it, but are pleasantly cured and thoroughly extirpated by it, as well as the highest and most inveterate State of the confirm'd Venereal Disease, which, with all its most raging Symptoms, it soon eradicates, restoring Health, Strength, and Vigour to the Body. Those who once take it, will never have Recourse to any thing else. One Pot in most Cases is sufficient for a Cure, and can now be had only at Mr. Eglinton's (Mr. Radford being deceas'd) at the Golden Pair of Spectacles against the East End of the New Church in the Strand, London, at 6s. a Pot, seal'd up with a Book of Instructions, by which all Persons may fully understand their own Condition, and certainly know when, and when not, the

- Two John Radcliffes appear on the roll of the Royal College of Physicians (published by W. Monk). One was made a Fellow in 1724 and died in 1729; the other became a Fellow in 1687 and died in 1714. Sir Samuel Garth was elected a Fellow in 1693 and died in 1718 .
Venereal Poyson is rooted out of their Bodies.

Note, Ask only for a Six Shilling Pot for the Scurvey. No Letters answer'd unless Post-paid.

Nineteenth-Century Advertisements

The Lancaster Gazette of Nov. 27, 1813, has the following advertisement.

\section{EVERY MAN HIS OWN DOCTOR. *}

BY the EFFICACY of Dr. BOERHAAVE's INFALLIBLE RED PILLS, (4s. 6d. only per box), PERSONS OF EITHER SEX (assisted by the invaluable copious directions therewith given) are enabled to eradicate effectually

A CERTAIN INSIDIOUS DISEASE, and to facilitate the recovery of health, with ease and safety, certainty and secrecy, in a few days.

For bilious diseases, scurvy, scrofula, and impurity of blood, the efficacy of this medicine is so well known and highly attested for $\mathbf{5 0}$ years past, that any further comment is rendered unnecessary.

Another supply is just received from London, and for sale by W. Minshull, Printer of this Paper, Lancaster ; Branthwaites, Kendal ; Addison, Preston ; and Mrs. Lyon, Wigan.

The Blackburn Alfred of Aug. 14, 1833, says : MERCURY is the Death of Thousands. Salivation exploded and Health restored. DR. HOFFMANN'S $\ddagger$ BOTANICAL PILLS. A never failing cure for a certain Disorder, in all its various stages and forms. That cruel Disease, which is so dreadful a scourge for illicit pleasures, is now, unhappily, so well known, that a recital of its effects is quite unnecessary. When it was first introduced into Europe, the greatest Physicians of the age were unable to combat its dreadful ravages, its virulent effects extended by inheritance, from family to family; and when the illustrious Dr. Hoffmann was raised to the Professor's Chair in the University of Halle, by the Great Frederick William, King of Prussia, to whom he was first Physician, he conferred an invaluable benefit on mankind, by undertaking the task and discovering an infallible Remedy for the cure of this shocking complaint.

To Dr. Hoffmann was reserved the signal happiness of discovering a botanical preparation for the cure of this disorder. Salivations, as dangerous as the complaint itself, had before been in use, and have even lately been too freely adopted by those who have been ignorant of a better and more perfect method of cure ; and these Pills,

* Herman Boerhave of Leyden was practising from 1688 to 1738.

$\$$ Frederick Hoffmann of Halle was practising from 1660 to 1672. None of the four physicians mentioned in these advertisements contributed anything outstanding to the treatment of venereal diseases, but they seem to have been mentioned as being leading medical authorities of the day. 
which have been so. famous through Germany, Prussia, Poland, and the Continent of Europe, for upwards of a century, are far superior to every other Remedy ever yet devised. These Pills are a SOVEREIGN remedy, for they root out and extirpate every particle of the disease, and banish it from the constitution, in every shape or form in which it may appear. As a certain cure they may be confidently relied upon.

Not less important is the question, Is this Remedy safe? And herein its virtues far excel all others; for while it is speedy and certain in its operation, it does not contain one particle of Mercury (of which too many Preparations are principally composed) but being entirely made up of Botanical Ingredients, can do no injury to the most delicate habits, buit going to the foundation of the Disorder, expels the poison, and as it were, creates the man anew.

These invaluable Pills may be taken with the greatest secrecy; they occasion no hindrance of business, loss of time, or restraint of diet, and are the most safe, speedy, pleasant, and efficacious remedy ever discovered for the complete cure of this insidious and malignant disease. They are peculiarly valuable for persons going abroad, or on long journeys, as their virtues remain unimpaired in all climates.

A bill of copious and particular directions is given with each box, describing the different stages of the complaint and the proper methods of treatment, by attending to which the patient is certain to cure himself with security and safety.

And the same journal for Nov. 6, 1833, has the following.

CUBEBS WITH SARSAPARILLA, $\dot{\&}$. STIRLINGS REES' ESSENCE-The vast and increasing sale, from the recommendation of the highest medical characters, as well as those who have experienced its salubrious and beneficial effects, proves its great success and decided superiority over every other preparation, it being the most safe and effectual remedy ever discovered for the cure of Gonorhoea, Gleets, Seminal Weakness, Strictures, Whites, Pains of the Loins, Kidnies, Gravel, irritation of the Bladder, Urethra, and all Disorders of the Urinary Passages, frequently performing a perfect cure in the short space of three or four days. It contains, in a highly concentrated state, all the efficacious parts of the Cubeb, chemically combined with Sarsaparilla, and other choice alteratives, which render it invaluable to those afflicted with secondary Syphilitic Symptoms, Ulcers, Pimples, Blotches, Scorbutic Eruptions, Glandular Swellings, and all other diseases arising from a tainted or impure state of the blood. In cases of debility, both local and general, tabes, dorsalis, wasting, impotence, and nervous depression of spirits, it has been taken with the most decided benefit. A regular perseverence in its use has invariably been found to improve digestion, and give muscular strength, energy, and vigorous health to the whole system. The most delicate female may take it with perfect safety. It is an excellent substitute for mercury.

Prepared only by J. W. Stirling, 86 Whitechapel, from whom it can be sent to any part of the world, upon enclosing a remittance, in bottles at $4 \mathrm{~s} .6 \mathrm{~d}$., 10 s, 20 s, and 36 s. each.

- Be sure the name " J. W. Stirling" is on the stamp.

WOOD AND MORRICE agents for Blackburn and neighbourhood.

Again the Blackburn Alfred, for Feb. 19, 1834, has :

\section{VENEREAL DISEASE, OR SYPHILIS}

This Horrid Disorder, which not only afflicts the present generation but remains in the blood for generątions to come, may in a few months be stopped in its career, by all persons of both Sexes, in certain cases, washing themselves well with a moderate strong lather, made of Tub, or Soft Soap, or if this is not at hand, with the best Yellow hard Soap, that which smells of Turpentine; or, six or eight hours after, with two drachms of good Soap Lees, mixed with eight ounces of pure water.

A WISE NATION will not be deterred by interested individuals from profiting from this salutary information.

The Burnley Advertiser of June 25, 1864 announces :

THE THREE DAYS' CURE-NEW FRENCH REMEDY THERAPION, as uniformly adopted in the French hospitals and by the notabilities of the French faculty ; in a remarkably short time, often two or three days only, without the slightest discomfort, inconvenience, or risk, removes all discharges from the mucous membrane, whether of the urinary or other organs. It combines all the desiderata to be sought in a medicine of the kind, and surpasses everything hitherto employed. Devoid of all unpleasant taste and smell. In packets 2s. 9d., 4s. 6d., 11s. and 33s. through all respectable medicine vendors, or sent direct from the establishment on receipt of stamps or post office order. The 11s. size contains three at $4 \mathrm{~s}$. $6 \mathrm{~d}$., and those at 33s. four of the 11s.

The stamp, to imitate which is felony, bears the word 'Therapion' in white letters, by order of Her Majesty's Hon. Commissioners, who thereby secure the proprietor against infringement throughout the United Kingdom and the colonies. 